\title{
Ciências Humanas na educação profissional: um olhar sobre as ações pedagógicas dos professores do Curso Técnico Integrado em Informática do IFRN/Campus Caicó
}

\author{
Humanities in professional education: \\ a glance at educational actions in Integrated Technical \\ course in computer Science at IFRN/Campus Caicó
}

\author{
Sandra Maria de Assis* \\ Olívia Morais de Medeiros Neta**
}

\section{RESUMo}

O presente estudo discute as práticas pedagógicas dos professores das disciplinas de Ciências Humanas do Curso Técnico Integrado em Informática do Instituto Federal de Educação, Ciência e Tecnologia do Rio Grande do Norte (IFRN)/Caicó e suas relações com o Currículo Integrado partindo da concepção dos docentes. Prossegue com a análise dos relatos acerca das ações pedagógicas apontadas como mais recorrentes no cotidiano escolar que dependem de um conjunto de operações didáticas coordenadas entre si, convergindo para a realização da tarefa de ensinar múltiplas funções dentro e fora da

\section{Abstract}

The present study discusses the pedagogical practices of teachers in the disciplines of Humanities Course in Computer Integrated Technical Federal Institute of Education, Science and Technology of Rio Grande do Norte (IFRN)/Caicó and its relations with the integrated curriculum starting from the design of teachers. Continues with the analysis of the reports about the pedagogical actions identified as most prevalent in everyday school life that depend on a set of didactic operations coordinated among themselves converging to carry out the task of teaching multiple functions inside and outside the class-

\footnotetext{
* Mestra em Educação Profissional pelo Programa de Pós-Graduação em Educação Profissional do Instituto Federal do Rio Grande do Norte (PPGEP/IFRN). Especialista e graduada (Licenciatura) em História pela Universidade Federal do Rio Grande do Norte (UFRN). Professora de História do Instituto Federal de Educação, Ciência e Tecnologia do Rio Grande do Norte (IFRN).sandra.assis@ifrn.edu.br

** Doutora em Educação pela Universidade Federal do Rio Grande do Norte (UFRN). Mestra e graduada em História pela Universidade Federal do Rio Grande do Norte (UFRN). Professora do Departamento de Educação da UFRN e do Programa de Pós-Graduação em Educação Profissional do Instituto Federal do Rio Grande do Norte (PPGEP/IFRN). olivianeta@gmail.com
} 
sala de aula e obrigando os docentes a mobilizarem conhecimentos sociais e culturais do currículo para encaminharem sua ação pedagógica. Ação que se faz com interpretação crítica, produção e organização de conhecimentos, identificação e escolha das técnicas e métodos pedagógicos para a socialização da aprendizagem com os sujeitos envolvidos no processo de ensinar/aprender. Palavras-chave: práticas pedagógicas; Ciências Humanas; educação profissional. room forcing teachers to mobilize social and cultural knowledge of the curriculum to forward their pedagogical action. This is done with critical interpretation, production and organization of knowledge, identification and selection of educational techniques and methods for the socialization of learning with the subjects involved in the process of teaching/learning.

Keywords: pedagogical practices; $\mathrm{Hu}-$ manities; professional education.

As práticas pedagógicas são aquelas ações escolares que acontecem em sala de aula. Essa definição emprestada de Sacristán (2000) será a base norteadora das discussões em torno das práticas pedagógicas dos professores das disciplinas que, conforme os Parâmetros Curriculares Nacionais, compõem a área das Ciências Humanas e suas tecnologias no Ensino Médio Integrado à Educação Profissional.

A definição do que sejam práticas pedagógicas, a princípio, nos parece insuficiente para dar conta da complexidade inerente à tarefa de ensinar, pois decerto o processo de ensino e aprendizagem se faz também em ambientes alheios à sala de aula. Tais práticas consistem em ações que envolvem um professor e seus alunos, ações que envolvem alunos e um grupo de professores, de especialistas de ensino, ou ainda, a comunidade escolar como um todo. (Soares, 1989). Falar de práticas pedagógicas, portanto, implica inicialmente uma compreensão de seu conceito.

Para Sacristán (1999), a prática pedagógica é entendida como uma ação do professor no espaço de sala de aula em que o docente assume a função de guia reflexivo, ou seja, é aquele que ilumina as ações em sala de aula e interfere significativamente na construção do conhecimento do aluno. As práticas pedagógicas não são neutras e carregam em si as concepções dos docentes a respeito de todo o processo educativo e escolar, suas subjetividades, seus valores e suas contradições. Compreendê-las no contexto escolar é muito importante para a produção do conhecimento no campo da Educação. 
Com base nesse entendimento, examinamos as práticas pedagógicas dos professores das disciplinas de Ciências Humanas do Curso Técnico Integrado em Informática do Instituto Federal de Educação, Ciência e Tecnologia (IFRN) do campus de Caicó (RN) e suas relações com Currículo Integrado no sentido de materializar a formação integrada.

Nesses termos, essa é uma pesquisa qualitativa que se desenvolveu por meio da utilização das entrevistas semiestruturadas aplicadas aos docentes, sujeitos da pesquisa. Conforme Minayo (2013), a pesquisa, realizada a partir do método qualitativo, procura desvelar processos sociais que ainda são pouco conhecidos e que são realizados por grupos particulares, sendo seu objetivo e indicação final proporcionar a construção e/ou revisão de novas abordagens, conceitos e categorias referentes ao fenômeno estudado.

Elencamos como sujeitos da pesquisa os seis professores ${ }^{1}$ que lecionaram as disciplinas de História, Geografia, Sociologia e Filosofia em duas turmas do curso Técnico Integrado de Informática. As entrevistas orais foram gravadas e transcritas e realizaram-se em dois momentos.

Assim, a discussão das práticas pedagógicas parte da concepção dos docentes a respeito delas e prossegue com a análise dos relatos dos docentes acerca das ações pedagógicas apontadas por eles como as mais recorrentes no cotidiano escolar.

\section{As Cî̂nCias Humanas no CURRÍculo do ENSINO MÉDIO INTEGRADO À EDUCAÇÃO PROFISSIONAL}

A Lei de Diretrizes e Bases da Educação Nacional (LDBEN), de 1996, estabelece que o Ensino Médio seja a etapa conclusiva da Educação Básica para toda a população brasileira. Desse modo, fez-se necessário a superação do seu caráter dual: acadêmico/propedêutico ou técnico/profissional. Assim, essa etapa de formação deixa de ser apenas uma preparação para o prosseguimento dos estudos universitários ou para a atividade profissional e assume seu novo status: completar a educação básica.

Em quaisquer de suas modalidades se sobrepõem tarefas diversas como preparar para a vida, para o trabalho, para o exercício da cidadania e para o prosseguimento nos estudos em nível acadêmico. Para tanto, impôs-se a necessidade de articular áreas de conhecimentos, dando-lhes sentido e utilidade, 
no contexto da formação básica dos jovens com suas múltiplas aspirações e necessidades de formação para a vida.

Mais do que reproduzir dados, denominar classificações ou identificar símbolos, estar formado para a vida, num mundo como o atual, de tão rápidas transformações e de tão difíceis contradições, significa saber se informar, se comunicar, argumentar, compreender e agir, enfrentar problemas de qualquer natureza, participar socialmente, de forma prática e solidária, ser capaz de elaborar críticas ou propostas e, especialmente, adquirir uma atitude de permanente aprendizado. (Brasil, 2002, p.9)

Para alcançar tais metas é necessário que a escola ofereça meios para os alunos desenvolverem suas habilidades e adquirirem competências ${ }^{2}$ que lhes são exigidas pelo mundo do trabalho, para se construírem como cidadãos responsáveis, para fazerem escolhas, resolverem problemas, participarem efetivamente da sociedade como protagonistas.

Dessa perspectiva, os saberes escolares não podem ser vistos de forma fragmentada, sob pena de prejudicar a formação dos estudantes e comprometer o projeto de sociedade, que se pretende construir fundada, sobretudo, na autonomia e na participação social. Já está claro que o atual modelo de escola e de educação não condiz com o que está proposto nessas diretrizes e que, embora muitas delas já estejam em andamento, mudanças substanciais precisam ser implementadas. Arriscamos dizer que as mais importantes dizem respeito às práticas pedagógicas dos professores, o que inclui o trabalho interdisciplinar.

Trata-se de um tipo de trabalho só se efetiva através de uma prática docente comum na qual diferentes disciplinas mobilizem, por meio da associação ensino-pesquisa, múltiplos conhecimentos e competências, gerais e particulares, de maneira que cada disciplina dê sua contribuição para a construção de conhecimentos por parte do educando, com vistas a que ele desenvolva plenamente sua autonomia intelectual.

A área de Ciências Humanas tem como objeto mais amplo "o estudo das ações humanas no âmbito das relações sociais ... bem como as construções intelectuais elaboradas nos processos de construção dos conhecimentos ... necessários para o viver em sociedade, em termos individuais ou coletivos" (Brasil, 
2002, p.24). Seus conceitos estruturadores apresentam-se transversalmente em todas as disciplinas da mesma área de maneira explícita ou implícita.

Os conceitos estruturadores se articulam às três competências centrais da área expressas nos Parâmetros Curriculares Nacionais para o Ensino Médio/ MEC, quais sejam: representação e comunicação; investigação e compreensão; contextualização sociocultural.

A primeira competência relaciona-se com as linguagens, entendidas aqui como instrumentos de produção de sentido para toda e qualquer formulação do intelecto humano, além de referir-se também às diferentes formas de acesso, organização e sistematização de conhecimentos (PCNEM, 1999, p.296). A segunda refere-se aos diferentes procedimentos, métodos, conceitos e conhecimentos que são mobilizados e/ou construídos/reconstruídos nos variados processos de intervenção no real, que são sistematizados a partir da resolução de problemas relacionados às análises acerca da realidade social (PCNEM, 1999, p.296). Já a terceira refere-se à diversidade e, portanto, à constituição dos diferentes significados que saberes de ordem variada podem assumir em diversos contextos sociais (PCNEM, 1999, p.296).

Conforme os Parâmetros Curriculares Nacionais para o Ensino Médio (PCNEMs), as disciplinas específicas da área de Ciências Humanas definem-se por um objeto comum e por pontos de intersecção das metodologias específicas de produção desses conhecimentos, cujas especificidades ocorrem pelos focos diferenciados a partir dos quais vislumbram seu objeto em relação ao espaço (Geografia), ao tempo (História), à sociabilidade (Sociologia) e aos processos de reflexão sobre comportamentos e pensamentos (Filosofia), fatores dos quais decorrem peculiaridades metodológicas importantes a serem preservadas.

A área das Ciências Humanas organiza as disciplinas considerando a identidade delas com relação aos seus objetos de estudo e seus métodos de análise, que se constituem em campos organizados de trabalho e têm contribuições específicas e também complementares que não podem ser substituídas umas pelas outras, mas que precisam atuar enquanto disciplinas afins.

Compreender, através da produção do conhecimento científico, a natureza das práticas pedagógicas dos docentes dessa área de conhecimento pode ser uma oportunidade para dar mais relevância a esse campo do conhecimento 
e contribuir para ampliar seus espaços de ação e enunciação no contexto de formação para o trabalho, para a vida social, produtiva e participativa.

À medida que o professor produz e compartilha seus conhecimentos, ele os expressa por meio de suas práticas em sala de aula. Compreender tal processo implica a percepção de como o professor "aprende e ensina, como se constrói e se reconstrói, como transforma e é transformado" (Charlot, 2005, p.24). Portanto, investigar as práticas pedagógicas dos docentes torna-se necessário para a compreensão dos processos de transformação em que a escola e os sujeitos estão inseridos.

\section{PRÁtICAS PEDAGÓGICAS INTEGRADORAS NO ENSINO MÉDIO INTEGRADO À EDUCAÇÃO PROFISSIONAL}

O Ensino Médio Integrado foi criado pelo Decreto no 5.154/2004 em meio a um conjunto de embates ideológicos e profundas contradições. ${ }^{3} \mathrm{Um}$ dos pontos fortes dessas discussões se deu em torno da tentativa de ruptura com o dualismo vigente na educação brasileira e a possibilidade de garantir aos jovens uma formação integrada à educação profissional.

Essa possibilidade relaciona-se com o Currículo Integrado, que, por sua vez, está ligado a práticas pedagógicas que nos aproximem de uma leitura ampla da realidade, mesmo reconhecendo ser impossível uma apropriação cognitiva de todos os conhecimentos relativos a essa dita realidade (Araújo, 2013).

O Ensino Médio Integrado é uma proposta pedagógica que visa a um processo formativo cujo sentido remete à completude e ao amplo desenvolvimento das faculdades intelectuais e físicas dos sujeitos. Nessa concepção,

compreender o ensino integrado exige a crítica às perspectivas reducionistas de ensino, que se comprometem em desenvolver algumas atividades humanas em detrimento de outras e que, em geral, reservam aos estudantes de origem trabalhadora o desenvolvimento de capacidades cognitivas básicas e instrumentais em detrimento do desenvolvimento de sua força criativa e de sua autonomia intelectual e política. (Araújo, 2013, p.3) 
Isso significa reconhecer que a prática educativa tem um sentido, uma organização, uma intencionalidade e é mediada por um recurso discursivo entre o professor, o aluno e o conhecimento.

O professor é socialmente reconhecido como responsável pela materialização das ações pedagógicas no ambiente escolar, embora não seja o único, e sobre ele recai o compromisso de, sob certas condições, escolher as práticas pedagógicas apropriadas a cada situação de aprendizagem.

Não nos ocorre a ideia de que o Ensino Médio Integrado à Educação Profissional exija a aplicação de métodos e estratégias pedagógicas diferenciadas, mas sim de práticas orientadas pela ideia de integração na formação humana. Isso evidentemente não exclui a possibilidade da existência de práticas mais coerentes com os princípios e finalidades do Ensino Médio Integrado.

A título de orientação acerca dos projetos pedagógicos, Araújo (2013) faz as seguintes observações:

a) Em função das opções políticas, epistemológicas e metodológicas, cada projeto pedagógico é único;

b) Coerente com essas opções, cada projeto requer práticas formativas diferenciadas, capazes de identificar seu conteúdo;

c) Um projeto de ensino integrado, referenciado nos princípios formativos da escola unitária, pressupõe práticas pedagógicas coerentes com seus princípios e finalidades, mas não exclui outros procedimentos formativos promotores da integração parte-todo, teoria-prática e ensino técnico e profissional, no Ensino Médio.

Para o referido autor, a depender das turmas, da disciplina, das condições intelectuais dos sujeitos envolvidos, princípios e objetivos dos cursos e das escolas envolvidas, inúmeros procedimentos podem favorecer a compreensão de mundo na amplitude que o ensino integrado preconiza.

Sendo o Ensino Médio Integrado uma proposta orientada para desenvolver nos alunos a capacidade de compreender, amplamente, o mundo a sua volta em suas dimensões culturais, ético-políticas, econômicas e sociais, entendê-la e materializá-la exige que tenhamos o compromisso com práticas que não neguem aos estudantes, especialmente aos que já estão inseridos ou prestes a se inserirem no mundo do trabalho, o desenvolvimento de sua força criativa e de sua autonomia intelectual e política. Dessa perspectiva, Araújo (2013, p.3) assevera que "o desenvolvimento de práticas pedagógicas integradoras não 
depende apenas de soluções didáticas, elas requerem, principalmente, soluções ético-políticas".

A esse respeito, consideramos que a concretização das práticas que tornam a proposta possível depende do trabalho docente, de um conjunto de operações didáticas coordenadas entre si que convergem para a realização da tarefa de ensinar. Além de ter muito claro o projeto de homem e de sociedade no qual se baseia a proposta, o professor deve ter uma formação que o capacite para sua materialização.

Na verdade, não são as práticas em si, mas a atitude do professor e demais atores do processo educativo é que as fazem integradoras. Ressaltamos também que a promoção das práticas depende também de condições materiais concretas e conhecimento da realidade dos sujeitos da aprendizagem, bem como do ambiente em que vivem.

Nesse sentido entendemos que

são várias as possibilidades de arranjos pedagógicos e curriculares que favoreçam as práticas pedagógicas orientadas pela ideia de integração e em que são diferenciados os elementos de integração do ensino e da aprendizagem. A escolha por um arranjo depende de várias varáveis como as condições concretas de realização da formação, o conhecimento e a maturidade profissional do professor, o perfil da turma e o tempo disponível, mas, decisivo é o compromisso docente com as ideias de formação integrada e de transformação social. (Araújo, 2013, p.7)

Reiteramos que a opção dos professores por incorporarem às suas práticas docentes os elementos de integração do ensino e aprendizagem depende também de uma formação que lhes capacite para tanto. É certo que o compromisso é importante, mas sem as ferramentas de execução, fornecidas em parte pela formação e em parte pelas condições materiais e técnicas, pouco ou nada se poderá fazer.

Cabe-nos refletir, com base nos depoimentos dos docentes das disciplinas da área de Ciências Humanas, sobre como suas práticas pedagógicas se inserem no contexto do Ensino Médio Integrado à Educação Profissional. A partir dos depoimentos dos professores, discutiremos suas práticas, considerando a análise das seguintes categorias: as concepções de práticas pedagógicas; a organização do plano de trabalho; as atividades de pesquisa e extensão; o trabalho interdisciplinar e a avaliação. 
Ressaltamos que nas entrevistas, os sujeitos foram estimulados a falar de suas práticas nas turmas do Ensino Integrado do Curso Técnico de Informática (2011.1) do IFRN/Caicó, mas todos os docentes entrevistados desenvolvem atividades de ensino com turmas de outros cursos e modalidades e, inevitavelmente, essas experiências se refletem em seus depoimentos.

\section{CONCEPÇÃO E MATERIALIZAÇÃO DAS PRÁTICAS PEDAGÓGICAS NO ÂMBITO DO ENSINO MÉDIO INTEGRADO À EDUCAÇÃO PROFISSIONAL}

A metodologia, o planejamento e a avaliação, partes constituintes e constituídas pelas práticas dos docentes refletindo suas concepções pedagógicas no contexto da Educação Profissional, norteiam as análises que ora pretende-se neste trabalho.

Em relação às práticas iniciamos a abordagem perguntando como os professores as concebiam e à medida que iam discorrendo sobre isso também falavam de suas estratégias para desenvolvê-las. Veremos que suas concepções não divergem no essencial: a ideia de que as práticas pedagógicas se centralizam nas ações do professor para e com os alunos.

O professor de Sociologia diz que as práticas pedagógicas são as ações desenvolvidas por ele para viabilizar e construir o aprendizado com os alunos dentro e fora da sala de aula. Segundo ele, tais práticas são realizadas buscando-se adequá-las ao que está proposto pelo currículo sem desconsiderar a realidade do aluno e procurando fazer uma ligação com seu cotidiano, seus anseios e necessidades. Ao discutir política, por exemplo, ele procura mostrar que

é algo presente ... não é só a política partidária, ela está presente em várias relações que sejam coletivas e estão buscando interesses. Então pra mostrar isso eu dei um exemplo aqui da escola e em algumas salas isso repercutiu muito forte, aí eu percebi que eles se sentiam tocados por aquilo ali, envolvidos. (Prof. Josias)

Além dessa aproximação com o cotidiano da escola, o professor também considera importante adequar os conteúdos mais complexos para facilitar a compreensão dos educandos e, à medida que eles vão amadurecendo, vai utilizando textos mais difíceis para estimulá-los a pensar criticamente. 
Uma vez que o ano letivo é dividido em quatro bimestres, ele afirma que percebe uma diferença no rendimento dos alunos que repercute em suas práticas pedagógicas. No primeiro bimestre professor e alunos estão se conhecendo e as práticas desenvolvidas seguem um ritmo mais lento. No quarto bimestre ocorre o mesmo, em virtude da correria do fim do ano letivo e do cansaço físico e mental de professores e alunos. Nos segundo e terceiro bimestres o ritmo das atividades pedagógicas é mais intenso e rico em possibilidades para o trabalho docente.

O professor de História concebe as práticas pedagógicas como sendo tudo aquilo que é desenvolvido com os alunos em benefício do processo de ensino e aprendizagem, inclusive as atividades de pesquisa pensadas, desenvolvidas e articuladas ao ensino. Para ele, cuja formação foi fortemente direcionada para a pesquisa, essa prática é essencial na formação dos estudantes e deve estar permanentemente associada ao ensino.

Além disso, ele procura fazer com que sua disciplina História, pragmaticamente, ajude os alunos a perceber como se constrói o conhecimento histórico e como ele se relaciona ao seu cotidiano. Nesse sentido, o professor afirma:

procuro tratar da relação passado/presente evitando os anacronismos, mostrando que o passado se relaciona a esse mundo do trabalho em que o aluno está inserido. Eu trabalho com fontes históricas, que é para mostrar a construção do conhecimento histórico para que o aluno perceba que aquele conhecimento não é algo dado, que está lá bem organizado no livro didático, pronto para ser consumido, pra fazer uma prova e depois não ter nenhum significado. Vendo como o conhecimento é construído ele tem uma noção mais crítica do que é a história. Acho que, na medida do possível, tem dado certo para o aluno perceber o significado e a utilidade desse conhecimento para a formação dele, porque muitas vezes o aluno vê a História como uma disciplina mais teórica ou como um exercício de memorização de "decoreba" enfadonha e às vezes vem a comparação com as disciplinas técnicas que são mais práticas e o aluno também tem uma tendência a priorizar as disciplinas técnicas entendendo-as como mais complexas. Nesse sentido eu procuro mostrar que a disciplina de História também tem a sua complexidade e a sua utilidade. A tendência é que o aluno se envolva mais. Procurando contribuir para essa formação crítica, como vemos nos documentos que regem a área de ensino e o Projeto Político Pedagógico, acho que a disciplina de História é fundamental para essa formação crítica e voltada para o mundo do 
trabalho, também procurando fazer essa relação entre teoria e prática a partir da pesquisa. (Prof. Roberto)

As práticas pedagógicas mais recorrentes em suas aulas no decorrer de um ano letivo são as aulas expositivas dialogadas. Mas ele ressalta a advertência feita aos alunos de que, para o diálogo acontecer, depende de dois ou mais. E reconhece que em algumas aulas o diálogo não acontece e em outras ele até supera suas expectativas.

Sempre procuro fazer com que a aula seja dialogada. Acho que tenho procurado fazer questionamentos que instiguem mais os alunos e tenho muitas vezes questionado determinados alunos como uma maneira de envolvê-los mais diretamente. Procuro gerar o debate, sobretudo nas atividades avaliativas do dia a dia que muitas vezes são em grupos com um tempo determinado para eles discutirem nos grupos e depois um tempo para o debate com toda a turma. Sugiro temas para trabalhos com apresentações diversas e estimulo para que eles manifestem o que aprenderam de diversas maneiras. (Prof. Roberto)

Com relação aos seminários, não costuma fazê-los frequentemente, devido a experiências malsucedidas. Prefere indicar leituras e cobrá-las nas atividades avaliativas.

O professor João Carlos define práticas pedagógicas como sendo ações desenvolvidas pelos professores para facilitar o entendimento do conteúdo ensinado aos alunos. Ou seja, são as ações desenvolvidas para que ele (o aluno) possa ver e entender o contexto histórico e, enfim, servem para facilitar a aprendizagem. Entre elas, a mais recorrente é a aula expositiva dialogada cujas discussões e questionamentos favorecem não só o aprendizado do aluno como o do próprio docente. O professor diz não acreditar que possa haver "ensino e aprendizagem através de um monólogo do professor".

Questionado sobre como relaciona essas práticas ao currículo, João Carlos afirma:

procuro buscar elementos de certos conteúdos que se vivencia no mundo hoje ... quando trabalho, por exemplo, o Iluminismo, trabalho também o Liberalismo Econômico e, assim, eu não consigo fazê-lo sem refletir sobre o Neoliberalismo. Quando trabalho o tema da escravidão não dá pra deixar de trabalhar o racismo, preconceito, segregação racial na sociedade atual, estabelecendo pontes com isso. 
Eu acho que buscar elementos da realidade atual e sua relação ... quando se fala sobre os povos indígenas no período da colonização, a reflexão que se faz sobre o que se vê em jornais, sobre as populações indígenas, como é a política do Estado brasileiro com esses povos ainda hoje. Então eu acho que sempre estamos buscando o cotidiano, que é um elemento facilitador dessa aprendizagem.

Essa relação depende da forma como é elaborado o plano de trabalho, levando-se em consideração a realidade dos alunos, o que exige um conhecimento prévio sobre eles.

A organização das aulas, em geral, segue as diretrizes traçadas no planejamento e as características próprias de cada professor. No caso do professor João Carlos, a música é sempre utilizada como uma ferramenta de aprendizagem. Aliada às imagens, à fotografia, à pintura e aos documentos escritos, ela viabiliza as discussões e debates na sala de aula, mantendo-se o cuidado de contextualizar os acontecimentos, situando-os historicamente. Referindo-se às práticas desenvolvidas rotineiramente em sua sala de aula, o professor assim se posiciona:

Eu gosto de fazer discussões, debates, mesmo que não seja uma coisa sistematizada. A própria aula, geralmente, é conduzida como um debate. De trazer textos diferentes, trazer poemas, músicas e estimular o aluno a buscar a história nisso. Eu acho que os alunos do IFRN nessas duas turmas ... são muito participativos. Não dá, nem se você quisesse, para fazer uma educação bancária. Eles se colocam, eles reagem, se sensibilizam e eu percebo que quando eu trago pra aula esses instrumentos diferenciados (recursos didáticos) eles se interessam bem mais, um vídeo, um filme ... Gosto de seminários. Inclusive foi uma prática a que eu comecei a aderir mais depois que eu entrei no IFRN. E produções de materiais artísticos: ... peças, músicas, um telejornal, como se eles estivessem acompanhando os acontecimentos do período estudado. (Prof. João Carlos)

Segundo o professor, essas práticas tornam-se mais eficientes, sobretudo no ensino de História, à medida que o professor vai conhecendo a realidade dos alunos. "Acredito que sejam extremamente importantes, para que a História deixe de ser vista como algo entediante e sem relação com a vivência dos discentes". Para ele, a inserção de elementos da História e da cultura local enriquece o processo de ensino-aprendizagem. 
Também é importante que os alunos participem e se sintam à vontade para isso. Utilizar imagens, músicas, vídeos e outros recursos didáticos ajuda a despertar o interesse e a curiosidade dos alunos e mobiliza suas impressões sobre o conteúdo ministrado, possibilitando uma visão mais ampla e multifacetada do objeto estudado.

O professor de Filosofia, referindo-se ao currículo como um orientador de sua prática, afirma: "uma prática pedagógica que se coloca acima das injunções curriculares é perigosa. Há que desenvolver-se em consonância com os trilhos curriculares". Para ele,

a prática pedagógica deve estar ligada à vida, ao existir. Deve-se buscá-la de forma a se estar consciente de que a educação se vê diante de buracos negros, como lembra Morin. A prática pedagógica deve ser uma busca de se vencer esses buracos. (Prof. Antônio)

Conscientes de que pisamos num terreno repleto de incertezas, contamos com o currículo, senão como algo dado, pelo menos como uma luz a nos apontar o caminho a ser percorrido. Se será fácil ou difícil, bem ou malsucedido, vai depender das práticas pedagógicas que optamos por desenvolver. $\mathrm{E}$ elas, por sua vez, resultam das escolhas do professor e das condições sócio-históricas.

As práticas pedagógicas, embora se desenvolvam essencialmente na sala de aula, extrapolam os ambientes escolares e ganham contornos mais democratizantes, distanciando-se dos modelos denominados por Paulo Freire de 'educação bancária', que veem o aluno como um repositório de saberes, muitas vezes fragmentados e desconectados de sua realidade.

O Professor de Geografia, ao falar de suas práticas pedagógicas, reporta-se ao educador Paulo Freire para assinalar seu esforço de fugir do estigma das aulas expositivas, vistas como chatas e desinteressantes. Ele afirma a importância dessa prática, argumentando que cabe ao professor estudar, planejar e estimular de diversas formas a participação dos alunos e a dinamização das aulas. Se o tema é interessante, se faz sentido para sua vida, se a aula é conduzida de forma a atrair sua atenção e a estimular sua participação, o aluno vai gostar, independentemente de ser aula expositiva ou não.

Buscar um ambiente agradável na sala de aula, no entender de Caio César, depende mais da boa vontade do professor do que de recursos pedagógicos 
sofisticados. Ele afirma que, às vezes, a própria configuração espacial da sala, quando alterada, já contribui para elevar a disposição dos alunos, deixando-os mais propensos a prestarem atenção à aula e aumentando a interação da turma com o professor.

Essa relação afetiva que se estabelece entre o professor e seus alunos, conforme o professor Caio César, também se deve à preocupação que ele sente por zelar pela autoestima dos alunos, mostrando-lhes que todos podem aprender e que suas dificuldades são comuns a outros estudantes como eles.

Entre as práticas citadas pelo professor como as mais exitosas em seu fazer pedagógico estão os seminários, as aulas de campo e as aulas expositivas dialogadas. Os seminários, devido à autonomia que conferem aos educandos na construção do conhecimento; as aulas de campo, devido à oportunidade de fazerem um trabalho interdisciplinar (um professor dificilmente faz aula de campo sozinho) e as aulas dialogadas, graças às discussões e aos debates que elas proporcionam. Além disso, também menciona seu gosto pela leitura e interpretação de mapas em conjunto com os alunos, bem como a prática dos júris simulados, quando tem de tratar de temas mais polêmicos em que é preciso discutir posições contraditórias, para demonstrar aos alunos a necessidade de conhecer e conviver com as diferenças.

A professora de Geografia, ao se reportar às práticas pedagógicas, as define como as atividades pedagógicas que os professores desenvolvem na escola, sendo moldadas de acordo com o perfil das suas turmas e de acordo com o planejamento feito para a abordagem dos diferentes conteúdos no dia a dia das salas de aula. Ela afirma que nem sempre as turmas reagem aos estímulos de aprendizagem da mesma forma, daí a necessidade de adequações, tendo-se o cuidado de não perder o currículo de vista, posto que as práticas devam ser sempre orientadas por ele.

No contexto da educação profissional, os conteúdos ensinados devem ter relação com o mundo do trabalho. Quanto a esse aspecto, a professora refere-se a alguns desses conteúdos afirmando que sua disciplina permite tal correlação.

Acredito que a Geografia, quando trata de população, de economia, como é que essa população está inserida na economia, qual o papel, a questão da globalização, questão da revolução técnico-científica-informacional ... então o papel dessas pessoas que estão sendo formadas para o mercado do trabalho, acredito que 
tem tudo a ver, e às vezes quando eu estou falando de algum tema, no caso da revolução técnico-científica-informacional, tento trazer exemplos de como isso afeta a realidade deles como futuros profissionais nessa área, de Informática. (Prof. Juliana)

A preocupação com a realidade das turmas, segundo a professora, deve ser um elemento norteador do planejamento e se reflete na organização das suas aulas suscitando várias indagações: o que está posto no currículo? Como deve adequar o conteúdo aos interesses da turma? Como tornar o conteúdo mais fácil e mais atraente? Vai resultar em aprendizagem significativa?

A partir desse diagnóstico, a professora planeja suas aulas procurando desenvolver práticas que envolvam os alunos:

nas minhas aulas procuro sempre trazer questões para os alunos refletirem, fazer com que eles participem também, com que eles se interessem pelo tema, interajam, sintam curiosidade em perguntar, em fazer uma análise ... porque muitas vezes o aluno lê o livro didático, mas não pensa sobre o que lê ... Tento trazer, ao analisar um determinado assunto, os dois lados: a forma como o autor do texto expõe e como isso se mostra na realidade do aluno. Um exemplo foram os seminários em que eles fizeram uma análise da realidade deles, de mostrar como acontece localmente, para eles conseguirem associar isso que vemos em sala de aula que parece uma coisa muito distante, que só está nos livros, mas que na verdade também acontece no próprio ambiente em que eles convivem, na cidade em que estão morando. (Prof. Juliana)

Vê-se, na fala da docente, a preocupação em ensinar algo que seja significativo, que repercuta positivamente no cotidiano de seus alunos, não apenas o conhecimento, mas o modo como sua apreensão pode fazer diferença na vida dos alunos. Nesse sentido, além dos seminários, a prática de promover debates é vista pela professora como uma maneira de estimular a aprendizagem, pois possibilita o confronto de pontos de vista diferentes e demonstra aos alunos que uma única temática pode ser analisada de diversas formas.

Para Juliana, desenvolver nos alunos a capacidade de argumentar, de analisar criticamente, deve ser sempre um objetivo das disciplinas da área de Ciências Humanas e a Geografia. Em particular, é importante para a formação na medida em que trabalha novas ideias e interpretações, em escalas em que o local e o global definem-se numa verdadeira rede que comunica pessoas, 
funções, palavras e ideias. Desse modo, a utilização de vídeos, filmes, fotografias e outras imagens que estimulem o pensamento são estratégias sempre recorrentes em sua prática pedagógica.

Como dito anteriormente, as práticas pedagógicas cotidianas são direcionadas por um plano de trabalho orientado pelo currículo. Nesse sentido, o planejamento se insere como uma ação didática essencial ao trabalho docente.

O planejamento é um elemento revelador das intenções e da sistematização das práticas pedagógicas e das demais ações educativas da escola. Sua elaboração relaciona-se ao Projeto Político Pedagógico e não tem de ser, necessariamente, formal e burocrática, mas uma prática coletiva e participativa, cabendo ao professor conhecer seu significado e ter consciência de sua articulação com o currículo.

Podemos dizer que, além de ser um ato de tomada de decisão, o planejamento, assim como o currículo, também é um ato ético e político. Não é uma ação neutra, não é um fim em si mesmo. Articula-se com a avaliação e com o Projeto Político Pedagógico (PPP), seguindo um caminho que passa pelo diagnóstico da realidade e pela estruturação das ações, uma vez definidos objetivos, os conteúdos, os procedimentos didáticos, os recursos e a avaliação.

Os professores são os responsáveis pela elaboração e execução bem-sucedida do planejamento no âmbito da escola e da sala de aula, o que lhes confere um amplo poder para intervir na configuração do perfil pedagógico e didático da escola. Nesse sentido, saber o que pensam sobre o planejamento e como fazem uso dessa ferramenta didática é muito importante para compreendermos as práticas dos docentes entrevistados.

Na elaboração de seu plano de trabalho, o professor Josias leva em consideração a origem social da turma; a relação que estabelece com ela e o horário em que as aulas serão ministradas. Considera também relevantes os conceitos estruturadores que margeiam sua disciplina, as habilidades e competências envolvidas, bem como o nível dos alunos, para pensar em um plano de trabalho que considere os prováveis conhecimentos dos estudantes, buscando desenvolver, aprimorar e refinar suas habilidades e competências.

Na discussão sobre política, por exemplo, o professor utilizou o estudo de caso, problematizando algumas situações cotidianas, dispondo-as para os alunos analisarem, fazendo-os pensar sobre os desafios que estavam postos, 
estimulando a discussão e o debate. Além dessa prática, costuma servir-se dos estudos de textos, seminários e entrevistas.

Uma preocupação do professor Roberto é planejar suas atividades pedagógicas cotidianas sem perder de vista o currículo. Tendo-o como algo que não enrijece sua prática pedagógica, considera que o currículo está integrado a seu fazer pedagógico. Sobre o plano de trabalho de sua disciplina, o professor afirma que consulta as diretrizes gerais do currículo, fazendo, na medida do possível, uma ligação com a proposta de formação integrada e pensando em alguns temas relacionados ao mundo do trabalho. No início de cada bimestre revisa a proposta curricular e prepara um cronograma das aulas do período (dez datas que correspondem a vinte horas/aula), distribuindo os temas das aulas de acordo com a grade curricular e deixando a última data para a prova.

De acordo com João Carlos, para efetuar o planejamento é preciso fazer escolhas e elencar dentro do PPC (Projeto Pedagógico do Curso) aquilo que é mais interessante para a formação que se tem em mente, o que não é tarefa fácil. Também é importante estabelecer uma relação entre o plano de trabalho e a realidade dos alunos, o que exige um conhecimento prévio sobre eles.

Dessa perspectiva, Antônio afirma recorrer às constantes leituras para elaborar seu plano de trabalho. A cada aula busca maneiras de levar a seus alunos não só o conteúdo advindo dessas leituras como também meios para convertê-los em leitores, uma vez que não os concebe de outra forma. Sua prática pedagógica constrói-se na busca de uma ligação do saber escolar ao existir de cada discente.

O planejamento, de acordo com o citado professor,

deve ser uma atividade meticulosa e, ao mesmo tempo, dinâmica, em decorrência da exiguidade do tempo que se coloca disponível ao profissional do magistério. Deve estar embasado na realidade vivida pelos discentes e em conformidade com as aspirações pedagógicas do professor. Além desse embasamento, a conjuntura político-econômica apresentada pela realidade não pode se encontrar ausente, isso pelo fato de a escola não ser uma ilha isolada de um continente, mas parte integrante desse todo. Consciente dessa assertiva, bibliografia compatível com essas aspirações é consultada, como também o pensamento que se lhe opõe, porque o contraponto se faz necessário. Outro fator que não se faz ausente são os graus de dificuldade apresentados pelo corpo discente em sala de aula. (Prof. Antônio) 
A forma como o professor concebe o planejamento sinaliza para suas práticas na sala de aula, em que as ações são sempre direcionadas para o objetivo de envolver os alunos, embora isso nem sempre seja possível. Procura estabelecer o diálogo, uma vez que, como o próprio professor Antônio afirma, "a sala de aula não é uma via de mão única" e o saber escolar deve estar relacionado ao contexto no qual os alunos se inserem.

Para Caio César, o planejamento das aulas é fundamental para o êxito de sua prática. Nessa ocasião, faz um roteiro dos temas a serem estudados, seleciona a bibliografia, pensa na metodologia e nas estratégias a serem utilizadas em sala e de que forma vai avaliar a aprendizagem dos alunos ao final de cada encontro. Para ele, conhecer as diretrizes do currículo ajuda muito nessa definição do rumo a ser seguido em aula.

O meu plano de trabalho é elaborado a partir do PTDEM (Proposta de Trabalho das Disciplinas do Ensino Médio), que é a nossa bússola no que tange ao roteiro dos conteúdos a serem trabalhados em cada nível e série. Em seguida, penso como vou adotar essa ou aquela metodologia de trabalho, sempre levando em consideração o nível das turmas e o cuidado com o pré-requisito trazido pelos alunos. Vejo também quais serão as minhas estratégias e como, quando e onde preciso implementá-las. A avaliação leva em conta toda essa gama de fatores, pois ela não pode estar deslocada de todo esse processo. $\mathrm{O}$ mais importante a considerar nessa tarefa é a condição de aprendizagem de cada aluno e todos no conjunto. (Prof. Caio César)

Garantir a aprendizagem dos alunos parece ser a principal preocupação do professor quando do planejamento de suas aulas e isso se evidencia quando ele nos lembra da necessidade de criar um ambiente de aprendizagem agradável e descontraído que faz da sua sala de aula um espaço de afetividade. Segundo ele, os primeiros momentos das aulas são destinados a essa tarefa, independentemente da forma como a aula foi planejada: exposição de conteúdos, seminário, estudo de texto, correção de atividades, debate, prova, aula de campo etc.

A avaliação e sua relação com as práticas pedagógicas dos professores de Ciências Humanas são elementos apresentados no Projeto Político Pedagógico do Cefet/RN (2006), segundo o qual a avaliação deve priorizar a qualidade, a aprendizagem e o desempenho do aluno no decorrer do período letivo. Assim 
sendo, ela não pode se limitar a apenas uma prova ou trabalho escrito. A avaliação, dessa perspectiva, deve ser processual e contínua, numa busca de construção do conhecimento e do desenvolvimento de hábitos, atitudes e valores coerentes com uma formação que vá além da capacitação para o trabalho.

Os professores entrevistados demonstraram, por meio de seus depoimentos, que compartilham dessa orientação. Questionados sobre como avaliam seus alunos e o que levam em conta na hora de avaliar, suas respostas foram coerentes com o que propõe o PPP. No entanto, em seus relatos, algumas particularidades se evidenciam. Vejamos.

O professor João Carlos procura diversificar os instrumentos de avaliação, utilizando, além da prova escrita, seminários, pesquisas, produções textuais e debates. Acredita que dessa forma consegue lidar melhor com a diversidade da sala de aula e as diferentes competências/habilidades dos alunos.

A avaliação, na concepção de Josias, é um processo que também envolve aspectos subjetivos que dependem do diálogo, bem como da relação que se estabelece entre professor-aluno, cujas variáveis nem sempre é possível considerar totalmente. Ele procura levar em consideração as dificuldades dos alunos advindas da própria disciplina que ministra e as dificuldades que os alunos já trazem, como, por exemplo, as deficiências na leitura e compreensão de textos e de comunicação e expressão. Sua avaliação é realizada continuamente por meio de atividades em sala de aula, ou designadas como tarefa de casa, trabalhos, seminários, provas (com questões objetivas e subjetivas). Também são consideradas a presença e a participação nas aulas, bem como o envolvimento com as atividades inerentes à disciplina (discussões, debates).

O professor Roberto (História) diz que tem dúvidas quanto à avaliação contínua proposta pelo PPP, mas procura avaliar seus alunos continuamente conforme o seu entendimento desse conceito.

Eu tento fazer a avaliação contínua naquilo que eu entendo como sendo avaliação contínua. Eu faço algumas avaliações ao longo do bimestre à medida que vou dando os conteúdos e uma última avaliação que é a prova, cujo peso é de $50 \%$ da nota, mas varia de acordo com a importância das outras atividades desenvolvidas, que podem ser seminários, pesquisas, estudo de textos e outros trabalhos desenvolvidos, podendo a nota da prova ser menor do que a nota atribuída aos trabalhos. Eu procuro fazer com que a nota da prova não seja o único fim da avaliação. Ou seja, eu vou adaptando a avaliação à realidade que temos. Em cada 
pequena avaliação dessa eu procuro ver os progressos dos alunos. Corrijo todos os trabalhos. Nos trabalhos escritos eu sempre faço anotações, procuro o aluno pra saber por que ele não se saiu bem na avaliação, tento conversar pra ver se ele melhora nas seguintes e, quase sempre, depois desses trabalhos fazemos um breve debate para discutirmos a correção para ver se eles entenderam ou não. E o mesmo é feito com o resultado da prova. Na aula seguinte à prova sempre faço a correção e a sondagem das dificuldades que os alunos apresentaram naquele momento. (Prof. Roberto)

Dois aspectos do depoimento do professor nos chamam a atenção. $\mathrm{O}$ primeiro é sua preocupação com a aprendizagem e o uso que ele faz dos resultados para replanejar suas ações pedagógicas com vistas a melhorar os resultados dos alunos. O segundo é a forma como pondera os valores atribuídos às atividades avaliativas de acordo com sua contribuição para a aprendizagem, promovendo discussões em torno dos conteúdos abordados na avaliação. Outra preocupação do professor é com a reflexão sobre a prática. Ele afirma que foi modificando sua prática avaliativa à medida que foi ficando mais experiente. Ou seja, agregou os saberes experienciais aos saberes adquiridos em sua formação acadêmica. Sua fala vem corroborar tal afirmação.

Eu mudei muito as minhas avaliações do meu início como docente até agora. Tem certas coisas que se mantiveram, as questões têm que ser bem contextualizadas e procuro avaliar continuamente o aluno hoje muito mais do que ontem. É um processo de construção, buscando sempre o retorno dos alunos pra saber as dificuldades deles. Posso dizer que o que levo em conta em primeiro lugar é a aprendizagem e vou adequando os instrumentos de avaliação para ver quais se adequam melhor à aprendizagem dos meus alunos durante todo o bimestre. (Prof. Roberto)

A preocupação de Roberto com a escolha criteriosa dos instrumentos de avaliação denota o zelo pela aprendizagem que deve ser, a rigor, o fim último da avaliação.

Segundo Juliana sua disciplina aborda aspectos da realidade, do dia a dia, fazendo análise social, econômica, ambiental do meio em que os alunos estão inseridos. Suas práticas avaliativas tendem a contemplar essas particularidades e por isso ela prioriza as provas escritas dissertativas, mas também dá espaço a outras atividades avaliativas, como seminários, testes de múltipla escolha, relatórios de aulas de campo, confecção e leitura de mapas e gráficos e outros. 
A professora enfatiza que suas práticas avaliativas são pensadas e planejadas levando em conta também as características da turma a ser avaliada, pois, segundo ela, nem sempre um instrumento aplicado numa turma pode ser aplicado com o mesmo êxito em outra.

Antônio reafirma sua preocupação com os graus de dificuldade apresentados pelo corpo discente em sala de aula e com a aprendizagem de conteúdos que sejam significativos para os alunos. Nesse sentido, afirma que procura "realizar avaliações diagnósticas, que levam em conta o nível de aprendizagem e de cognição".

Para Caio César, a avaliação é o processo mais complicado para o professor e para os alunos na construção do conhecimento, pois a avaliação não pode estar desconectada daquilo que está em seu plano de trabalho.

Avalio meus alunos tomando por base, em primeiro lugar, aquilo que trabalhei em sala com eles. Mas permito, através de trabalhos fora de sala de aula (as chamas tarefas de casa), a viagem pelo conhecimento. A avaliação se dá através de trabalhos em grupo, seminários, prova individual, listas de exercícios em que dou o "visto" e depois as corrijo em um grande debate com os alunos, aulas de campo, entre outros.

A complexidade do ato de avaliar, sentida pelo professor Caio César, também transpareceu nos depoimentos de outros docentes. Isso porque avaliar não se resume à simples tarefa de aplicar provas e aferir notas. Conforme Libâneo (1994), os dados mensurados nesse processo devem ser submetidos a uma apreciação qualitativa, uma vez que a avaliação cumpre funções pedagógico-didáticas, de diagnóstico e controle, que atuam de forma interdependente.

Não se trata apenas de aferir o rendimento escolar em números, mas de identificar progressos e dificuldades, suscitar mudanças no processo de ensino, e também avaliar a capacitação dos alunos para seguir em frente, aptos para as exigências que a sociedade lhes impõe.

\section{CONSIDERAÇÕES FINAIS}

Em sentido amplo, a prática pedagógica é formada por um grande número de modelos e circunstâncias recebidos do outro, por meio de ideias, exemplos, sugestões. Nesse sentido a interação entre os professores torna-se importante e, algumas vezes, fundamental para uma boa atuação docente. Na diversidade 
da sala de aula, os docentes encontram a oportunidade de conhecerem novas experiências que combinadas com as suas experiências anteriores irão proporcionar um saber para a realização de novas práticas.

A prática docente no contexto da sala de aula não é um exercício meramente técnico, marcado pelo atendimento às prescrições curriculares desenvolvidas por outros. Os aspectos que perpassam a ação dos professores são múltiplos e complexos, portanto sua prática pedagógica não pode ser reduzida ao manejo de técnicas de ensino, mas consiste em uma mistura de habilidades que eles desenvolvem ao longo de sua trajetória profissional.

O professor é, cotidianamente, levado a analisar situações, refletir e tomar decisões referentes à aprendizagem de seus alunos. Além disso, na sala de aula, ele precisa mediar situações que nem sempre se resumem a questões relativas ao ensino dos saberes escolares propriamente ditos. Incontáveis vezes o professor precisa ser um gestor de conflitos, de sentimentos, de aspirações. Ser um articulador, um facilitador da aprendizagem. Essas múltiplas funções dentro e fora da sala de aula o obrigam a mobilizar conhecimentos a partir das análises dos fundamentos sociais e culturais do currículo, para encaminhar sua ação pedagógica. Ação que, por sua vez, se faz com interpretação e crítica, com produção e organização de conhecimentos, identificação e escolha das técnicas e métodos pedagógicos para a socialização das experiências de aprendizagem com os sujeitos envolvidos no processo de ensinar/aprender.

\section{REFERÊNCIAS}

ARAÚJO, Ronaldo M. de L. Práticas Pedagógicas e Ensino Integrado. In: REUNIÃO NACIONAL DA ANPED, 36., 29 set./2 out. 2013, Goiânia, GO. (Mimeo.)

ARAÚJO, Ronaldo M. de L.; COSTA, Ana Maria R.; SANTOS, Manuela T. Organização do trabalho pedagógico e ensino integrado. Revista Trabalho necessário, ano 11, n.17, 2013. Disponível em: www.uff.br/trabalhonecessario; Acesso em: 14 abr. 2015.

CENTRO FEDERAL DE EDUCAÇÃO TECNOLÓGICA DO RIO GRANDE DO NORTE (CEFET). Projeto Político Pedagógico do CEFET. Natal, 2005.

CHARLOT, Bernard. Relação com o saber, formação de professores e globalização: questões para a educação hoje. Porto Alegre: ArtMed, 2005.

BRASIL. Ministério da Educação. Orientações curriculares para o ensino médio: ciências da natureza, matemática e suas tecnologias, 2. Brasília: SEB, 2006. Parâmetros Curriculares Nacionais: ensino médio. Brasília: Semtec, 1999. . PCN+ensino médio: orientações educacionais complementares aos Parâme- 
tros Curriculares Nacionais. Ciências Humanas e suas tecnologias. Brasília: Semtec, 2002.

BRASIL. Presidência da República. Decreto n. 5.154, de 23 de julho de 2004. Regulamenta o $\$ 2^{\circ}$ do art. 36 e os arts. 39 a 41 da Lei $\mathrm{n}^{\circ} 9.394$, de 20 de dezembro de 1996, que estabelece as diretrizes e bases da educação nacional, e dá outras providências. Diário Oficial da União, Brasília, 2004. Disponível em: http://portal.mec. gov.br/setec/arquivos/pdf1/proejadecreto5154.pdf; Acesso em: 10 set. 2013.

FREIRE, Paulo. Pedagogia da autonomia: saberes necessários à prática educativa. São Paulo: Paz e Terra, 1996.

FRIGOTO, Gaudêncio; CIAVATTA; Maria; RAMOS, Marise (Org.) Ensino médio integrado: concepção e contradições. São Paulo: Cortez, 2005.

LIBÂNEO, José Carlos. Didática. São Paulo: Cortez, 1994.

MINAYO, Maria Cecília de S. O desafio do conhecimento: pesquisa qualitativa em saúde. 13.ed. São Paulo: Hucitec, 2013.

SACRISTÁN, J. Gimeno. O Currículo: uma reflexão sobre a prática. 3.ed. Porto Alegre: Artmed, 2000.

. Poderes instáveis em educação. Porto Alegre: ArtMed, 1999.

SOARES, Magda B. Alfabetização no Brasil: o Estado do conhecimento. Brasília: Inep/ MEC, 1989. Metamemórias: travessia de uma educadora. São Paulo: Cortez, 1991.

\section{NOTAS}

${ }^{1}$ Os professores entrevistados para esta pesquisa colaboraram com narrativas de suas histórias de vida e de atuação profissional. Foram ao todo seis professores, que, no decurso do texto, aparecem com nomes fictícios: professores Artur (Filosofia); Roberto e João Carlos (História) Caio César e Juliana (Geografia) e Josias (Sociologia).

${ }^{2}$ Não há definição única ou universal para as competências, que são qualificações humanas amplas, múltiplas e que não se excluem entre si. Por exemplo, os PCN para o Ensino Médio explicitam três conjuntos de competências: o de comunicar e representar, o de investigar e compreender, assim como o de contextualizar social ou historicamente os conhecimentos (Brasil, 2002).

${ }^{3}$ A esse respeito consulte-se Frigotto; Ciavatta; Ramos (2005). No capítulo 1 os autores discutem o processo contraditório que envolveu a revogação do Decreto n 2.208/97 e a construção do Decreto n 5.154/2004.

Artigo recebido em 17 de julho de 2016. Aprovado em 9 de setembro de 2016. 